\title{
Analisis Strategi Pengembangan Bisnis E-Commerce Pertamina Retail dengan Pendekatan Bisnis Model Kanvas
}

\section{Analysis of Pertamina Retail E-Commerce Business Development Strategies with a Canvas Model Business Approach}

\author{
Prori Vitaliano Latief ${ }^{1 *}$, Rizal Syarief ${ }^{2 *}$, dan Rokhani Hasbullah ${ }^{3 *}$
}

\author{
${ }^{1}$ Mahasiswa Program Magister Manajemen Bisnis, Sekolah Pascasarjana, Institut Pertanian Bogor \\ 2 Departemen Ilmu dan Teknologi Pangan, Fakultas Teknologi Pertanian, Institut Pertanian Bogor \\ ${ }^{3}$ Departemen Teknik Mesin dan Biosistem, Fakultas Teknologi Pertanian, Institut Pertanian Bogor \\ * Jl. Kamper Kampus IPB Darmaga Bogor 16680
}

\begin{abstract}
ABSTRAK
Persaingan bisnis industri bahan bakar di Indonesia sudah sangat ketat. Suatu perusahaan dapat tertinggal dari pesaing dibidangnya, apabila perusahaan tersebut tidak dapat berkembang mengikuti kemajuan zaman. Di era saat ini kemajuan teknologi memiliki peran penting untuk meningkatkan bisnis perusahaan. PT Pertaminan Retail merupakan sebuah perusahaan besar di bidang industri bahan bakar Indonesia. Penelitian ini bertujuan untuk menganalisis desain pengembangan model bisnis e-commerce dari PT Pertamina Retail yang bernama MyPertamina. Metode yang digunakan adalah business model canvas (BMC), metode Delphi, SWOT (Strenghts, weakness, opportunities, and threats) dan Blue Ocean Strategy. Data yang digunakan dalam penelitian ini adalah data sekunder yang didapat dari studi literasi instansi penyedia data primer dengan teknik wawancara kepada enam orang narasumber. Waktu penelitian dimulai sejak November-Desember 2018. Dari hasil pemetaan model bisnis awal menggunakan BMC yang menunjukan beberapa aspek dari setiap unsur seperti: customer segment, value proposition, channels, revenue stream, key resources, key activities, key partner, dan cost structure. Analisis lingkungan menggunakan metode Delphi yang menunjukan nilai tren kunci 25,48\%, kekuatan industri 25,19\%, kekuatan pasar 24,78\%, dan kekuatan ekonomi makro 24,55\%. Lingkungan internal MyPertamina dipengaruhi oleh aspek produk, infrastructure management, customer interface, dan financial aspect. Hasil dari analisis SWOT (strenghts, weakness, opportunities, \& threats) terhadap sembilan unsur BMC menunjukan bahwa unsur yang memiliki kekuatan tertinggi adalah key partnership dan terendah adalah customer relationship. Sementara itu, peluang terbesar adalah value proposition dan yang terendah adalah cost structure. Ancaman tertinggi yaitu customer segment, dan ancaman terendah adalah key partners. Pengembangan model bisnis berdasarkan penelitian ini difokuskan pada customer segment, key partnership, dan value proposition, unsur dikembangkan menggunakan metode blue ocean strategy.
\end{abstract}

Kata kunci: BMC, e-commerce, MyPertamina

ABSTRACT

The competition of oil and gas industri in Indonesia is very tight. To get survive from the competition; the company has to develop their technology. Nowadays, technological advancement have salient roles in improving the company's business. PT Pertaminan Retail is a large oil and gas company in Indonesia. This study analyzed the design of e-commerce business development models from PT Pertamina Retail called MyPertamina. The method of the study is descriptive analysis and using business model canvas (BMC), the Delphi method, SWOT (Strenghts, weakness, opportunities, \& threats), and the Blue Ocean Strategy. The datas in this study were secondary dan primary data. The secondary data obtained from the literature study and the primary data was by interviewing six informants. The research period starts from November to December 2018. The results of mapping the initial business model that used BMC, showed several aspects such as: customer segments, value propositions, channels, revenue streams, key resources, key activities, key partners, and costs structure. Environmental analysis used the Delphi method and the result was key trend value was $25.48 \%$, industri strength was $25.19 \%$, market strengths was $24.78 \%$, and macroeconomic strengths was $24.55 \%$. MyPertamina's internal environment

\footnotetext{
*) Korespondensi:

Program Magister Manajemen Bisnis, Sekolah Pascasarjana, IPB Jl. Raya Pajajaran, Bogor; email: prori.vitaliano@gmail.com
} 
influenced by product aspects, infrastructure management, customer interface, and financial aspect. The results of the SWOT analysis of nine BMC unsurts showed that the highest strength was the key partnership and the lowest strength was customer relationship. Meanwhile, the biggest opportunity was value proposition and the lowest opportunity was cost structure. The highest threat was customer segment, and the lowest threat was key partners. The business development model in this research focused on customer segment, key partnership, and value proposition, unsurts developed using the blue ocean strategy method.

Key word: BMC, e-commerce, MyPertamina

\section{PENDAHULUAN}

Minyak bumi atau petroleum atau biasa disebut bahan bakar fosil merupakan bahan baku untuk pembakaran utama yang paling banyak digunakan oleh masyarakat dunia saat ini. Peningkatan permintaan untuk minyak mentah dan juga dengan kekhawatiran ketersediaanya menyebabkan harga minyak mencapai rekor tertinggi dalam sejarah pada tahun 2000-an.

PT Pertamina (Persero) menjadi aktor utama dalam pengembangan minyak bumi, serta energi-energi terbarukan melalui beberapa anakanak perusahaan seperti PT Pertamina Retail sebagai aktor utama yang berperan sebagai Badan Usaha Milik Negara (BUMN) dalam kegiatan pemasaran untuk minyak dan gas bumi di Indonesia.

PT Pertamina Retail terus berupaya mencapai rencana jangka panjangnya yang bertujuan untuk menjadi Perusahaan ritel global berkelas dengan memberikan nilai dari diversifikasi bisnis Ritel Bahan Bakar dan Non-Bahan Bakar melalui produk dan jasa yang terintegrasi tahun 2017. Di masa mendatang, PT Pertamina Retail akan mengoptimalkan dan terus mengembangkan aset dan infrastruktur yang dimiliki demi mempertahankan keunggulan kompetitif menjadi perusahaan yang memberikan kontribusi lebih bagi Perusahaan Induk dan Negara, dan tetap terus berpegang kepada komitmennya sebagai Perusahaan yang menjunjung profesionalisme, akuntabilitas dan berorientasi pada kenyamanan dan kepuasan pelanggan sebagaimana dikutip dari Corporate Profile PT Pertamina Retail (2018).

Persaingan bisnis hilir bahan bakar minyak di Indonesia di ramai oleh beberapa perusahaan besar, yaitu Pertamina, Shell, Total, Petronas dan yang terbaru adalah Vivo. Faktanya, satu per satu pesaing asing rontok, salah satunya adalah SPBU (Stasiun Pengisian Bahan Bakar Umum) Petronas milik Malaysia. Dengan semakin banyaknya pemain di hilir baik dalam distribusi dan penjualan BBM (Bahan Bakar Minyak), maka kondisinya akan semakin kompetitif, tetapi yang diuntungkan adalah konsumen.

Perusahaan dituntut melakukan antisipasi dalam menghadapi perubahan lingkungan yang sangat beragam dan tidak tentu. Antisipasi terhadap perubahan ini terdiri dari rencana atau strategi perusahaan yang diperlukan dan dianggap mampu menangani perubahan lingkungan tersebut. MyPertamina dapat diharapkan dapat menjadi salah satu strategi pemasaran yang mencakupi seluruh lapisan masyarakat Indonesia, sehingga bantuan PT Pertamina Retail, dan PT Pertamina (Persero) dapat dijadikan sebagai salah satu Perusahaan Minyak Bumi berbasis internasional.

Saat ini, eksistensi E-Commerce dijadikan sebagai salah satu alternatif strategi pemasaran yang berpengaruh pada peningkatan ekonomi suatu perusahaan. Menurut Survei yang dipublikasikan oleh APJII (Asosisasi Penyelenggara Jasa Internet Indonesia) pada tahun 2017, tingkat persentase terbesar dalam penetrasi pengguna internet sebanyak 143,26 juta jiwa atau $54,68 \%$ dari total populasi Indonesia. Dilihat dari grafik pertumbuhan pengguna internet di bawah ini, dapat disimpulkan penggunaan internet memiliki perkembangan sangat nyata setiap tahunnya, dimana saat ini per tahun 2017 jumlah pengguna internet di Indonesia mencapai 143,26 juta jiwa dibandingkan pada Tahun 2016 yang mencapai 132,7.

Melihat perkembangan E-Commerce yang semakin pesat, PT Pertamina Retail memutuskan memanfaatkan karakter masyarakat Indonesia yang cukup IT Oriented untuk peningkatan pendapatan Perusahaan. Salah satu strategi pemasaran yang telah dilakukan oleh PT Pertamina Retail adalah MyPertamina. Aplikasi MyPertamina merupakan sebuah aplikasi berbasis smartphone dan E-Money card yang dibuat kepada konsumen setia Pertamina sebagai bentuk loyalitas konsumen kepada Pertamina. MyPertamina memiliki beberapa fitur yakni e-Money yang dapat digunakan untuk pembelian Produk Pertamina seperti Pertamax Turbo dan Pertamax 
Dex Lite, pembelian merchandise Pertamina, dan transaksi di official retail Pertamina: Bright Store. Eksistensi dari MyPertamina ini dapat memudahkan konsumen untuk membudayakan cashless society yang merupakan instruksi dari Bank Indonesia akan pentingnya masyarakat berbasis cashless society.

Namun sejak pertama kali diluncurkan MyPertamina tahun 2017 hanya mendapatkan download 10000, masih sangat jauh dari yang diharapkan. Berdasarkan hal tersebut penulis berkeinginan untuk melakukan penelitian kenapa hal tersebut bisa terjadi, menggunakan metode Businees Model Canvas (BMC) yang merupakan yang dapat menggambarkan model bisnis yang digunakan dan untuk pengembangan model bisnis terbaru menggunakan metode Blue Ocean Strategy yang diharapkan akan membuka jalan keluar untuk meningkatkan performance dari unit bisnis MyPertamina. Menurut Stefan dan Richard (2014) konsep bisnis model Osterwelder dan Pigneur merupakan konsep bisnis model yang paling kompleks dan secara jelas menggambarkan tidak hanya secara ekonomi dan bisnis proses tetapi jug acara menciptakan nilai.

Tujuan penelitian adalah (1) Mengidentifikasi model bisnis E-Commerce yang dilaksanakan PT Pertamina Retail; (2) Mengembangkan model bisnis E-Commerce PT Pertamina Retail dimasa yang akan datang; (3) Memberikan rekomendasi strategi dan program E-Commerce PT Pertamina Retail dalam menghadapi persaingan.

\section{METODE PENELITIAN}

Pemilihan lokasi penelitian dilakukan dengan sengaja (purposive) di PT Pertamina Retail yang merupakan anak perusahaan PT Pertamina (Persero). Sumber data yang digunakan adalah data primer dan sekunder. Data primer didapatkan melalui wawancara mendalam kepada responden terpilih di internal perusahaan, yaitu manajemen yang bertanggungjawab pada kuncikunci kegiatan perusahaan yang digunakan dalam mengidentifikasi sembilan unsur BMC. Informasi internal dan eksternal perusahaan digunakan sebagai dasar pembuatan model bisnis perbaikan.

Data sekunder didapatkan melalui studi literatur di instansi penyedia data. Infromasi tersebut digunakan untuk mendukung keputusan strategis perusahaan kedepannya. Informasi yang digunakan adalah jumlah kompetitor, kekuatan kompetitor, market share, kondisi sosial ekonomi masyarakat wilayah pasar perusahaan. Selain itu digunakan juga sumber lain yang dianggap relevan seperti jurnal ilmiah dan buku.

Tahap pengolahan dan analsisi data yang dilakukan dengan pemetaan model bisnis saat ini menggunakan $\mathrm{BMC}$, analisis lingkungan internal dan eksternal dengan metode Delphi, evaluasi sembilan unsur BMC dengan metode SWOT, dan membuat rancangan model bisnis dengan Blue Ocean Strategy (BOS).

\section{HASIL DAN PEMBAHASAN}

PT Pertamina Retail (selanjutnya disebut Perusahaan) merupakan anak Perusahaan PT Pertamina Retail yang bergerak di bidang usaha retail produk Pertamina. Perusahaan didirikan pada tanggal 17 Juni 1997, dan awalnya bernama PT Pertajaya Lubrindo bergerak di bidang usaha Pelumas. Pada tanggal 1 September 2005, perusahaan berganti nama menjadi PT Pertamina Retail. Perubahan ini bertujuan menghadapi perubahan pasar retail khususnya SPBU (Stasiun Pengisian Bahan Bakar Umum) di Indonesia menuju pasar bebas dunia

PT Pertamina Retail membuat suatu inovasi berdasarkan perkembangan teknologi yang bisa mengubah uang, bisnis, dan dunia. Penggantian ini adalah keberlanjutan dari revolusi industri pada zaman dulu dimana banyak buruh pabrik yang digantikan dengan mesin/otomatisasi. PT Pertamina Retail membuat inovasi, yaitu MyPertamina. MyPertamina adalah gabungan dari loyalty program Pertamina dan penggunaan electronic money atau cashless payment. Penggunaan electronic money ini dilakukan dengan dua metode yaitu dengan kartu atau aplikasi smatphone.

\section{Pemetaan Model Bisnis}

Identifikasi pola model bisnis dilakukan dengan wawancara kuesioner yang bertujuan mendapatkan gambaran dan keterangan mengenai sembilan unsur blok Model Bisnis Kanvas yang merupakan sarana termudah untuk mengerti pola dengan bisnis suatu perusahaan. Wawancara kuesioner dilakukan kepada manajemen dan pelaksana dari MyPertamina seperti customer segment, value propositions, customer relationship, channels, revenue stream, key partners, key activities, key resources, dan cost structures. Model bisnis MyPertamina dapat dipetakan seperti pada Gambar 1. 


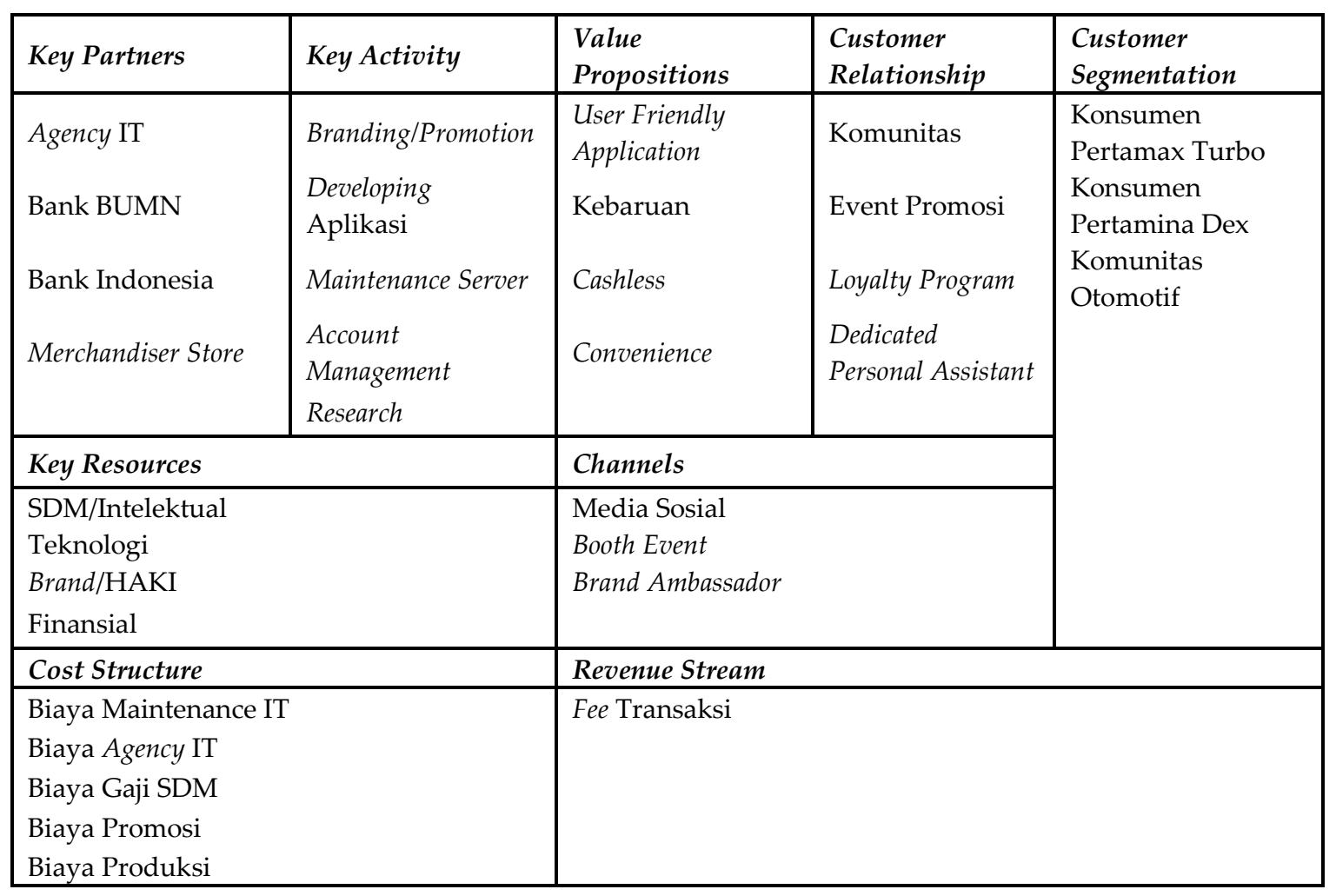

Gambar 1. Pemetaan bisnis model MyPertamina dengan BMC

\section{Customer Segment}

Bisnis MyPertamina terfokus dalam penentuan Customer Segment berdasarkan jenis produk yang dipasarkan. Pembagian segmentasi ini menjadi pertamax turbo. Konsumen dari Pertamax Turbo adalah pemilik dari kendaraan terbaru dengan paduan mesin canggih sehingga membutuhkan bahan bakar bermutu tinggi. Pengguna mengharapkan beberapa keunggulan dari Pertamax Turbo. Segmentasi berikutnya adalah Pertamina Dex, selain memiliki Cetane Number (CN) 53 dan rendah sulfur bisa membersihkan mesin, mencegah karat, kontamisasi air dan foaming. "Pendek kata Pertamina Dex" sangat tepat bagi kendaraan diesel yang menginginkan performa maksimal dan powerful. Segmentasi berikutnya yaitu komunitas otomotif, pada dasarnya penggiat otomotif juga pengguna bahan bakar minyak, komunitas ini dijadikan customer segment untuk pengembangan kegiatan marketing, karena pada dasarnya komunitas otomotif juga pengguna Pertamax Turbo atau Pertamina Dex.

\section{Value Proposition}

Menurut Kaplan \& Norton (2001), value proposition adalah suatu nilai yang disalurkan, dikomunikasikan, dan diketahui. Value proposition dapat diaplikasikan kepada seluruh organisasi, konsumen, produk atau layanan. Aplikasi My-
Pertamina dianggap memiliki karakteristik user friendly karena kemudahan dalam penggunaan fiturnya dan juga tampilannya yang sederhana dan minimalis membuat konsumen mudah dalam memahami dan menjalankan aplikasi dengan baik.

Menurut Drucker (1996), Inovasi atau kebaruan dilakukan dengan menciptakan sumber daya produksi baru maupun pengolahan sumber daya yang sudah ada, dengan tujuan pertambahan nilai potensi. Pertambahan nilai ini dilakukan dengan teknologi terkini guna mengakomodir keinginan dan kebutuhan konsumen Pertamina. MyPertamina merupakan inovasi dari PT Pertamina Retail yang bertujuan menarik konsumen baru dan mempertahankan konsumen lama dengan bantuan teknologi terkini.

Convenience atau kenyamanan menurut Suki (2002) dapat ditentukan sebagai faktor pendorong pengambilan keputusan pembelian secara online. Kenyamanan terkait waktu, ruang, dan penghematan yang dilakukan konsumen, tidak ada antrian atau kepadatan dan waktu. Seider et al (2000) memberikan empat jalan untuk memberikan kenyamanan, yaitu kenyamanan akses, pencarian, possession, dan kenyamanan transaksi. 


\section{Channels}

Channels merupakan gambaran dari cara perusahaan mengkomunikasikan dan menyampaikan value propositions, distribusi, serta penjualan kepada pelanggan. Kotler \& Keller (2008), menjelaskan tiga macam saluran pemasaran yang meliputi: communication channels, distribution channels, dan service channels.

MyPertamina menyadari bahwa media sosial merupakan sebuah platform yang sangat tepat untuk meningkatkan brandnya, dengan media sosial facebook dan Instagram. Banyaknya event otomotif dan komunitas membuat MyPertamina memasukkan booth pada event-event tersebut sebagai media penyampaian value produk kepada calon pelanggan.

MyPertamina menggunakan seorang brand ambassador dengan tujuan membangun brand awareness MyPertamina dan menggiring pelanggan baru menggunakan produk MyPertamina.

\section{Customer Relationship}

Customer Relationship memperlihatkan pola dan jenis hubungan yang dibangun oleh MyPertamina dengan pelanggan. MyPertamina menyadari bahwa hubungan dengan komunitas diharapkan menjadi wadah untuk menyaring informasi dan masukan dari pengguna MyPertamina, dan komunitas mendapat timbal balik yang sesuai seperti support event komunitas.

Usaha MyPertamina dalam meningkatkan indeks hubungannya dengan konsumen adalah dengan inisiatif atas beberapa loyalty program yang diharapkan dapat meningkatkan tingkat loyalitas kepada konsumennya. Usaha MyPertamina yang ketiga adalah Dedicated Personal Assistant. MyPertamina menyadari bahwa aplikasi yang mendapatkan perhatian banyak dari konsumen harus memiliki pelayanan sangat profesional dan didedikasikan untuk memberikan kemudahan kepada pelanggannya.

\section{Revenue Stream}

Unsur Revenue Stream ini memperlihatkan pendapatan yang diperoleh perusahaan pada setiap segmentasi pelanggan Dalam kasus MyPertamina, MyPertamina mendapatkan pendapatan dari Service Revenue. Dalam menggapai jenis pendapatan ini, MyPertamina menerapkan fee transaksi pada saat konsumen melakukan transaksi atau top up menggunakan saldo MyPertamina. Hal ini merupakan strategi utama MyPertamina dalam meningkatkan service revenue mereka, karena MyPertamina yakin bahwa jenis pendapatan ini akan selalu memberikan kontribusi yang berkelanjutan pada pendapatan MyPertamina.

\section{Key Partners}

Key Pertners didefiniskan sebagai sebuah hubungan antara pemasok atau mitra dengan sebuah perusahaan, sehingga model bisnis dapat berjalan. Perusahaan-perusahaan menjalin hubungan rekanan dengan berbagai alasan, dan hal tersebut menjadi landasan dari berbagai macam model bisnis.

IT Agency adalah bentuk kerjasama yang dihasilkan antara MyPertamina dengan pihak berhubungan dengan produksi dan maintenance aplikasi. Bank BUMN adalah bentuk kerjasama ini bersifat kontraktual, karena MyPertamina juga melihat tingkat atensi masyarakat terhadap bentuk kerjasama ini melalui berbagai program promosi untuk meningkatkan respons masyarakat. Pemerintah Pusat adalah MyPertamina perlu meningkatkan atensi khusus atas jenis hubungannya, karena MyPertamina sangat bergantung pada eksistensi pemerintah pusat dalam menentukan kelancaran dari aplikasi ini. Hubungan dengan Bank Indonesia saat ini, MyPertamina menggunakan system $e$-cash sebagai bentuk kepatuhan dalam kebijakan cashless society sebagaimana kebijakan tersebut merupakan inisiatif dari Bank Indonesia. MyPertamina tentu perlu mengevaluasi kembali lagi, untuk melihat apakah sistem pembayaran tersebut masih relevan dengan sifat masyarakat. Merchandiser Store adalah jenis hubungan yang terjadi adalah dalam menyalurkan penjualan secara offline, khususnya bagi masyarakat yang masih memiliki pengetahuan terbatas mengenai saluran penjualan merchandise MyPertamina.

\section{Key Activity}

MyPertamina menyadari pentingnya Key activity sebagai salah satu komponen penting aplikasi, sehingga timbul realisasi: (a) Application Branding, MyPertamina perlu sebuah aktivitas untuk meningkatkan brand recognition kepada masyarakat, dengan cara memanfaatkan brand ambassador untuk melakukan branding tersebut, (b) Application Development, MyPertamina menyadari bahwa dunia TI bergerak sangat cepat dan dinamis, sehingga pembaharuan aplikasi diperlukan, agar dapat menjangkau ke seluruh pemangku kepentingan MyPertamina, (c) Application Maintenance Server, Untuk peningkatan pelayanan atas masalah teknis pada aplikasi, (d) Account 
Management, Perlindungan data konsumen untuk menghindari spying dan information breaching dari perusahaan lain/pesaing, (e) Research, untuk mengetahui trend yang sedang diminati konsumen dan strategi yang diperlukan untuk menggapai tujuan tersebut.

\section{Key Resources}

Dalam konteks MyPertamina terdapat tiga Key Resources yang digunakan, yakni: (a) Sumber Daya Manusia (SDM), Sesuai dengan visi dan misi PT. Pertamina (Persero) bahwa SDM merupakan asset utama yang berkontribusi pada pembangunan perusahaan, karena SDM sangat memengaruhi arah kinerja Perusahaan. (b) Brand/Haki Kekayaan Intelektual, MyPertamina menyadari bahwa produk aplikasi ini dimiliki oleh perusahaan terkemuka, sehingga diperlukan proteksi atas aplikasi tersebut melalui pengembangan brand dan Hak Kekayaan Intelektual (HAKI), sehingga secara legal pesaing tidak dapat menjiplak sesukanya, dan agar MyPertamina memiliki identitas unik. c) Finansial, yang sangat penting bagi kegiatan operasional MyPertamina, melalui budgeting terstruktur dan detail.

\section{Cost Structure}

MyPertamina menjabarkan focus cost structure mereka ke dalam beberapa aspek, yang seperti: (a) Biaya Maintenance Teknologi Informasi, (b) Agensi Teknologi Informasi, (c) Gaji SDM, (d) Biaya Promosi, (e) Biaya Produksi.

\section{Analisis Lingkungan Internal}

Analisis lingkungan bisnsi internal dilakukan untuk memberikan gambaran dan pemahaman yang baik terhadap lingkungan bisnis yang dapat dikendalikan oleh perusahaan. Memahami lingkungan internal dilakukan dengan melakukan pemindaian struktur lingkungan internal yang menjadi bagian dari model bisnis MyPertamina. Hasil tersebut dijadikan bahan pertimbangan untuk merumuskan model bisnis yang lebih akurat dan kompetitif. Aspek lingkungan internal yang digunakan untuk penelitian ini meliputi product, customer interface, infrastructure management, dan financial aspect menurut Osterwelder dan Pigneur (2015).

\section{Product}

Identifkasi lingkungan internal pada MyPertamina mendapatkan faktor-faktor yang memengaruhi lingkungan internal pada aspek product, (fitur dan layanan, tingkat keamanan), User Experience, User Interface, dan Product Vol. 14 No. 1
Development. Perusahaan memberikan penilaian sangat penting pada aspek fitur dan layanan, tingkat keamanan, user experience, dan product development. Menutut perusahaan fitur, pengembangan produk, keamanan, dan kenyamanan konsumen dalam menggunakan produk merupakan hal utama untuk menjaga keberlangsungan perusahaan.

\section{Customer Interface}

Faktor-faktor yang dapat mempengaruhi Customer Interface dengan tingkat kepentingan yang pertama adalah Brand Activation, dan Media Infromasi. MyPertamina melakukan kegiatan brand activation pada saat launching hingga saat event-event otomotif, dengan membuka booth dan memperkenalkan produk kepada calon konsumen secara langsung untuk merasakan dan dipastikan menjadi salah satu konsumen baru.

Faktor berikutnya yang menjadi pertimbangan adalah media informasi, maka perusahan perlu membangun relasi dengan konsumen secara lebih dekat dengan adanya media infromasi kita memberikan informasi-informasi terbaru tepat sasaran dan efisien.

\section{Infrastucture Mangement}

Infrastructure management merupakan faktor yang berpengaruh pada bagian operasional perusahaan. Hal yang dianggap penting pada perusahaan meliputi ketrampilan SDM, budaya perusahaan, dan teknologi. Ketrampilan SDM merupakan salah satu faktor utama dalam membangun sebuah bisnis, karena SDM yang baik menghasilkan optimal pada kegiatan produksi, sama halnya dengan faktor teknologi, yang memadai, menghasilkan produktifitas dalam bekerja.

\section{Financial Aspect}

Hal yang berpengaruh pada aspek finansial MyPertamina meliputi kemampuan modal perusahaan, hubungan baik dengan konsultan IT, dan pengelolaan keuangan. Sebagai anak dari perusahaan besar, Pertamina Retail juga mengemban tugas penting pengembangan perusahaan secara umum, sehingga faktor kemampuan modal ini dapat diperhitungkan secara matang. Lebih banyak menggunakan fasilitas dan sarana yang telah tersedia, sehingga mengambil keputusan untuk menggunakan jasa konsultan IT yang dinilai kompeten. Besarnya biaya konsultan IT tersebut menekankan pada pengelolaan keuangan yang lebih baik. 


\section{Analisis Lingkungan Eksternal}

\section{Tren Kunci}

Analisis tren kunci mendapatkan peringkat persentase terbesar pertama dengan nilai $25.48 \%$. Analisis ini dilakukan berdasarkan aspek-aspek yang dianggap memengaruhi bisnis MyPertamina, yaitu tren masyarakat dan budaya, tren regulasi dan politik, tren sosio-ekonomi, dan tren teknologi. Pada lingkungan eksternal MyPertamina tren regulasi dan politik mendapat penilaian kepentingan terbesar, karena dipengaruhi oleh keberadaan Pertamina sebagai BUMN Indonesia yang setiap kegiatannya mendapat sorotan dari pemerintah pusat. Secara umum pemerintah melalui regulasi dan politiknya bisa memengaruhi secara langsung atau tidak langsung untuk mendukung atau mempersulit kegiatan bisnis MyPertamina.

\section{Kekuatan Pasar}

Aspek kekuatan pasar mendapatkan persentase terbesar ketiga setelah kekuatan industri $(24.78 \%)$. Penilaian tersebut menggunakan aspek-aspek yang dirasakan berpengaruh terhadap bisnis perusahaan. Aspek-aspek yang digunakan meliputi isu-isu pasar, segmentasi pasar, kebutuhan permintaan, biaya perpindahan, dan daya pikat pendapatan.

Isu-isu pasar mendapatkan penilaian tingkat kepentingan terbesar diantara aspekaspek lain. Isu pasar yang menjadi sorotan adalah cashless society. Sejalan dengan peraturan Bank Indonesia mengenai uang elektronik, banyak perusahaan mencoba menerapkan sistem electronic money berbasis cashless society. Menurut Dave (2016), terdapat beberapa manfaat dari cashless money, yaitu: (1) Memberikan kemudahan dan kenyamanan dalam transaksi; (2) Memberikan tingkat resiko yang lebih kecil; (3) Memberikan kendali pengaturan ekonomi.

\section{Kekuatan Industri}

Aspek kekuatan industri mendapat persentase penilaian kedua terbesar setelah tren kunci, yaitu $25.19 \%$. Penilaian tersebut menggunakan aspek-aspek yang berpengaruh terhadap bisnis MyPertamina, yaitu persaingan, pemain baru, produk dan jasa pengganti, pemasok, dan stakeholder.

Aspek persaingan mendapatkan penialaian tingkat kepentingan terbesar diantara aspekaspek lainnya. Menyadari pentingnya persaingan di bisnis hilir retail bahan bakar kendaraan, maka Pertamina Retail membuat suatu inovasi yang diharapkan cukup dan bisa membuat tetap bertahan sebagai market leader, yaitu MyPertamina. MyPertamina memanggul beban cukup berat sebagai inovasi yang mengikuti tren teknologi, disamping biaya yang dikeluarkan cukup besar.

\section{Kekuatan Ekonomi Makro}

Aspek kekuatan ekonomi makro mendapatkan persentase terkecil (24.55\%). Aspek kekuatan ekonomi makro ini dinilai menggunakan aspekaspek, yaitu kondisi pasar global, dan komoditas dan sumber daya lain. Aspek kondisi pasar global memiliki nilai kepentingan terbesar. Indikator nilai tukar mata uang yang melemah dan harga minyak dunia merupakan aspek dari kondisi pasar global yang mempengaruhi bisnis ECommerce Pertamina Retail.

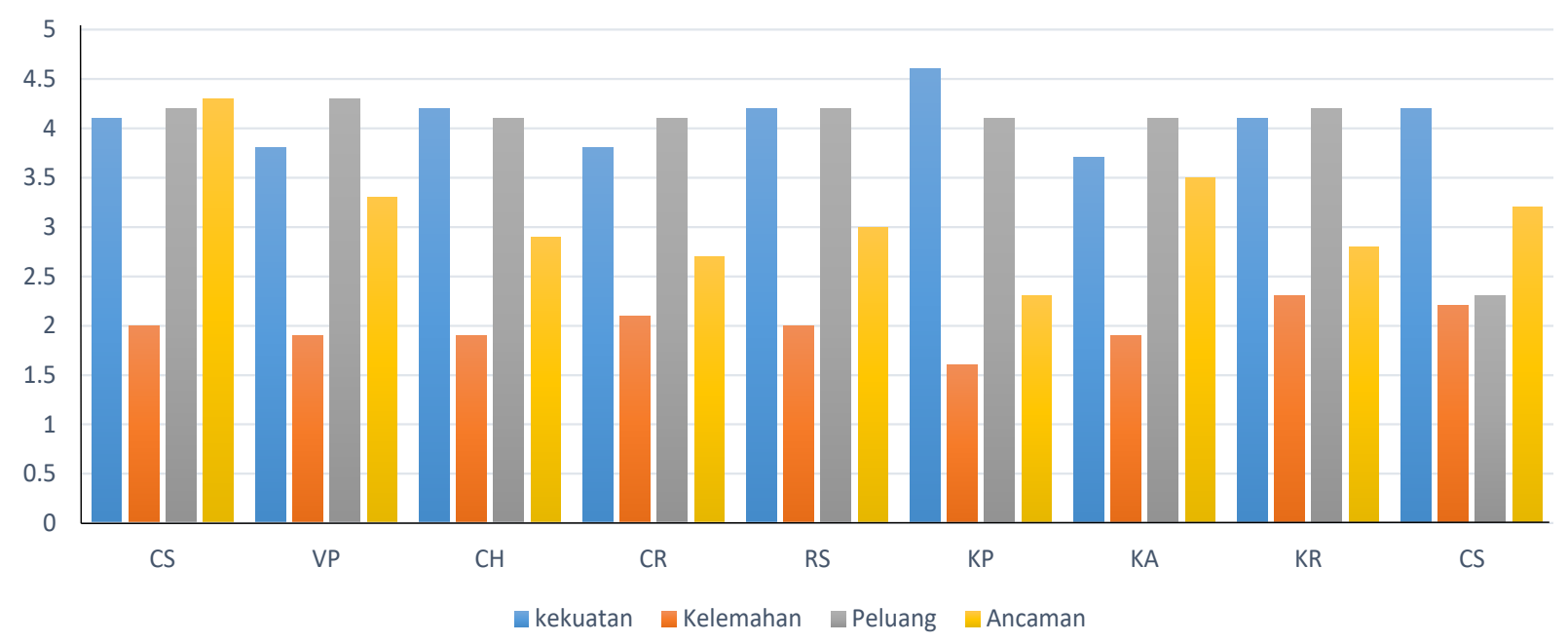

Gambar 2. Grafik SWOT pada sembilan unsur BMC 


\section{Evaluasi Model Bisnis}

\section{Customer Segments}

Hasil evaluasi customer segments memiliki kekuatan sangat tinggi $(4,1)$, kelamahan sangat rendah (2), peluang sangat tinggi $(4,2)$, dan ancaman sangat tinggi $(4,3)$. Peluang sangat tinggi disebabkan masyarakat Indonesia sudah mengetahui mutu dan nilai manfaat produk Pertamina yang membawa Indonesian Pride, sehingga masyarakat bangga menggunakan produk khas Indonesia.

\section{Value Propositions}

Hasil evaluasi value propositions menunjukkan kekuatan tersebut memiliki indeks cukup tinggi (3,8), kelemahan rendah $(2,1)$, peluang sangat tinggi $(4,1)$, dan ancaman $=$ cukup rendah $(2,7)$. Tingginya indeks peluang dalam segmen value propositions disebabkan oleh eksistensi Pertamina yang dianggap "memonopoli" penjualan produk petroleum.

\section{Customer Relationships}

Hasil evaluasi customer relationships mengindikasikan kekuatan berada pada indeks cukup kuat $(3,8)$, memiliki kelemahan yang sangat rendah $(2,1)$, peluang sangat tinggi $(4,1)$, dan ancaman cukup rendah $(2,7)$. Hal yang perlu digaris bawahi dalam tingginya indeks peluang dalam segmen ini adalah factor Pertamina telah berdiri lebih lama dibandingkan perusahaanperusahaan petroleum lainnya. Hal ini juga dipengaruhi oleh peran penting pemerintah Indonesia dalam meningkatkan hubungan Pertamina dengan konsumen melalui program subsidi BBM yang diharapkan dapat "mendekatkan" konsumen dengan Pertamina.

\section{Channels}

Hasil evaluasi segmentasi ini memiliki kekuatan sangat tinggi $(4,2)$, kelemahan sangat rendah (2), peluang sangat tinggi $(4,2)$, dan ancaman cukup tinggi. Tingginya indeks kekuatan dan peluang sebagian besar dipengaruhi oleh eksistensi anak perusahaan Pertamina yang diharapkan dapat menunjang efisiensi perusahaan, serta meningkatkan kontribusi ekonomi perusahaan tersebut.

\section{Revenue Streams}

Indeks evaluasi segmentasi revenue streams memiliki kekuatan sangat tinggi $(4,2)$, kelemahan sangat rendah (2), peluang sangat tinggi $(4,2)$, dan ancaman cukup tinggi (3). Tingginya indeks kekuatan dan peluang sebagian besar dipengaruhi oleh tingginya operational cost yang diberikan dari PT Pertamina Retail kepada MyPertamina, sehingga MyPertamina dapat memutuskan pihakpihak yang dapat diajak kerjasama dengan memiliki kompetensi tinggi.

\section{Key Activities}

Hasil observasi atas segmentasi ini memiliki indeks kekuatan cukup tinggi $(3,7)$, kelemahan sangat rendah $(1,9)$, peluang sangat tinggi $(4,1)$, dan ancaman cukup tinggi $(3,5)$. Tingginya indeks peluang dari segmentasi ini ditunjukkan dengan luasnya daerah distribusi sales dan marketing yang ditunjukkan dengan monopolisasi pasar petroleum dari PT Pertamina (Persero).

\section{Key Resources}

Hasil evaluasi key resources memiliki kekuatan sangat tinggi $(4,1)$, kelemahan sangat rendah $(2,3)$, peluang sangat tinggi $(4,2)$, dan ancaman rendah $(2,8)$. Tingginya indeks kekuatan sebagian besar dipengaruhi oleh banyaknya aspek intelektual, human, dan financial yang memadai, sehingga MyPertamina yakin bahwa aplikasinya dapat berkompetisi secara handal di pasar domestik.

\section{Key Partners}

Hasil evaluasi Key partners memiliki kekuatan yang sangat tinggi (4.6), kelemahan sangat rendah (1.6), peluang sangat tinggi (4.1), dan ancaman rendah (2.3). Indeks kekuatan yang tinggi disebabkan oleh tingginya indeks BuyerSupplier Relationships yang ditunjukkan dengan interaksi antara owner dan vendor.

\section{Cost Structure}

Hasil evaluasi cost structure memiliki kekuatan sangat tinggi (4.2), kelemahan sangat rendah (2.2), peluang sangat rendah (2.3), dan ancaman cukup tinggi (3.2). Indeks kekuatan yang sangat tinggi dipengaruhi oleh pelaksanaan strategi product-cost, service-cost, product line cost, dan customer cost. 


\begin{tabular}{|c|c|c|c|c|}
\hline Key Partners & Key Activity & Value Propositions & $\begin{array}{c}\text { Customer } \\
\text { Relationship }\end{array}$ & $\begin{array}{c}\text { Customer } \\
\text { Segmentation }\end{array}$ \\
\hline Agency IT & BRANDING/PROMOTION & $\begin{array}{l}\text { User Friendly } \\
\text { Application }\end{array}$ & KOMUNITAS & \multirow{10}{*}{$\begin{array}{l}\frac{\text { Konsumen }}{\text { Pertamax Turbo }} \\
\underline{\text { Konsumen }} \\
\underline{\text { Pertamina Dex }} \\
\text { KOMUNITAS } \\
\text { OTOMOTIF } \\
\text { Kendaraan Dinas } \\
\text { Pemerintah } \\
\text { Kendaraan Dinas } \\
\text { Swasta } \\
\text { Mitra Transportasi } \\
\text { Online }\end{array}$} \\
\hline BANK BUMN & DEVELOPING APLIKASI & Kebaruan & $\begin{array}{l}\text { EVENT } \\
\text { PROMOSI }\end{array}$ & \\
\hline Bank Indonesia & Maintenance Server & Cashless & Loyalty Program & \\
\hline $\begin{array}{l}\text { Merchandiser } \\
\text { Store }\end{array}$ & Account Management & CONVENIENCE & $\begin{array}{l}\text { Dedicated } \\
\text { Personal Assistant }\end{array}$ & \\
\hline $\begin{array}{l}\text { Perusahaan } \\
\text { Swasta } \\
\text { Pemerintah } \\
\text { Pusat } \\
\end{array}$ & Research & Prestige & & \\
\hline \multicolumn{2}{|l|}{ Key Resources } & \multicolumn{2}{|l|}{ Channels } & \\
\hline \multicolumn{2}{|l|}{ SDM/Intelektual } & \multicolumn{2}{|l|}{ Media Sosial } & \\
\hline \multicolumn{2}{|l|}{ Teknologi } & BOOTH EVENT & & \\
\hline \multicolumn{2}{|l|}{ Brand/HAKI } & \multicolumn{2}{|c|}{$B R A N D$ AMBASSADOR } & \\
\hline FINANSIAL & & \multicolumn{2}{|l|}{ Booth Activation } & \\
\hline \multicolumn{2}{|l|}{ Cost Structure } & \multicolumn{3}{|l|}{ Revenue Stream } \\
\hline \multicolumn{2}{|c|}{ Biaya Maintenance IT } & \multicolumn{3}{|l|}{ Fee Transaksi } \\
\hline \multicolumn{2}{|l|}{ Biaya Agency IT } & \multicolumn{3}{|c|}{ Afiliasi dengan pihak lain } \\
\hline \multicolumn{2}{|l|}{ Biaya Gaji SDM } & & & \\
\hline \multicolumn{2}{|l|}{ Biaya Promosi } & & & \\
\hline
\end{tabular}

Keterangan: Tebal/hijau (Menambahkan); Huruf besar/biru (Meningkatkan); Garis bawah/merah (Menghilangkan); dan Biasa/hitam (Tetap)

Gambar 3. Analisis pengembangan model bisnis MyPertamina

\section{Pengembangan Model Bisnis}

Menurut Giesen et al (2007) fokus pada inovasi model bisnis merupakan cara terbaik untuk menangani perubahan besar pada sebuah industry untuk meningkatkan daya saing perusahaan. Analisis Pengembanagan Model bisnis MyPertamina secara ringkas dijelaskan pada Gambar 3. Hasil analisis pengembangan model bisnis tersebut kemudian diarahkan pada aspek customer segmentation.

\section{Customer Segmentation}

Perubahan Customer Segmentation dari model bisnis MyPertamina akan berdampak luas pada pengembangan model bisnis mendatang. Perubahaan awalnya bersifat sangat spesifik menjadi lebih umum dengan banyak kriteria customer baru. Untuk itu diputuskan lebih fokus dan gencar pada kendaraan dinas pemerintah dan swasta yang diharapkan berguna dalam membantu memberantas fraud dilingkungan operasional yang berhubungan dengan bahan bakar kendaraan.

\section{Value Propositions}

MyPertamina perlu menambahkan nilai prestige dalam aplikasinya, melakukan integrasi dengan menyediakan beberapa merchandise yang dapat dibeli secara ekslusif dan terbuka bagi konsumennya bertransaksi melalui sistem poin. Sistem poin akumulasi hasil transaksi dari pembelian BBM Pertamax series. Selain itu, aspek prestige ini juga didapatkan dari sistem privilege bagi konsumen yang menggunakan MyPertamina "jalur khusus" pembelian bahan bakar di SPBU tertentu ini sebagai alat pembayaran di SPBU Pertamina.

\section{Customer Relationship}

Strategi lain yang perlu ditingkatkan oleh tim MyPertamina adalah strategi pendekatan kepada komunitas. Sebagaimana pada aspek customer segmentation, MyPertamina perlu memusatkan perhatian pada komunitas kendaraan bermotor, karena komunitas tersebut dinilai dapat memberikan loyalitaproduk yang lebih baik dan dapat memberikan kontribusi pendapatan yang besar. 
MyPertamina memberikan sebuah bargainning offer pada komunitas kendaraan tersebut tentang MyPertamina sangat fokus dan dekat dalam pemeliharaan mesin, sehingga komunitas tersebut yang untuk loyal kepada brand MyPertamina.

\section{Channels}

Keberadaan brand activation dalam mengembangkan bisnis MyPertamina, khususnya ke beberapa daerah terbelakang. Melihat hal tersebut, hal yang dapat dilakukan selain menggunakan brand ambassador MyPertamina, dengan social charity atau education charity yang diharapkan dapat mendekatkan MyPertamina dengan masyarakat.

\section{Revenue Stream}

Adanya mendapat pemasukan selain dari fee transaksi, melakukan hubungan afiliasi dengan pihak ketiga, unicorn Indonesia dibidang transportasi (Go-Jek). Dalam hal ini MyPertamina akan hadir sebagai solusi keuangan, dimana harus mencairkan terlebih dahulu dananya diaplikasi untuk membeli bahan bakar. Pertamina Retail tidak akan semudah itu menggunakan aplikasi Go-Pay untuk pembayaran karena kita memiliki MyPertamina untuk sarana pembayaran cashless, upaya yang eprlu dilakukan MyPertamina adalah bisa merubah jenis uang digital Go-Pay menjadi uang digital MyPertamina agar mitra Go-Jek bisa melakukan transaksi di SPBU secara cashless.

\section{Key Partners}

Guna mengantisipasi kurangnya performa bisnis perusahaan, hendaknya maka MyPertamina "terbuka" dengan perusahaan start-up yang lain, karena perusahaan-perusahaan ini dinilai dapat menjangkau konsumen lebih luas, sehingga memberikan pendapatan yang sangat besar.

\section{Key Activity}

Key activities dalam model bisnis MyPertamina masih dalam indikator minim, yaitu aplikasi yang perlu mendapatkan lesson learn, khususnya dalam kegiatan research and development, terkait pembaharuan fitur-fitur teknologi atau jenis layanan lainnya.

\section{Key Resources}

Unsur yang sangat penting dalam peningkatan mutu Key resources pada model bisnis MyPertamina adalah peningkatan budget pada aplikasinya. Apabila tim manajemen bersedia Vol. 14 No. 1 meningkatkan budget operasional pada pengembangan aplikasi tersebut, maka akan membantu aktivitas key resources yang lainnya, seperti pengembangan SDM, pengembangan teknologi, dan pengembangan brand atau HAKI.

\section{Cost Structure}

Secara keseluruhan, perlu ada keseimbangan antara empat unsur cost structure, mengantisipasi situasi akibat ketidakseimbangan dari masing-masing empat unsur cost structure tersebut. Sebagai contoh, untuk unsur maintenance IT, jika tim manajemen MyPertamina tidak mengalokasikan dana pada aspek maintenance IT, tentunya IT Agency bekerja secara tidak optimal sehingga bug-bug yang mengganggu performa aplikasi akan berjalan tidak baik.

\section{KESIMPULAN}

Identifikasi model bisnis MyPertamina menunjukan analisis internal aspek Product meliputi fitur dan layanan memiliki tingkat kepentingan terbesar, yaitu $25,98 \%$. Analisis eksternal menunjukan aspek tren kunci seperti tren regulasi dan politik dengan tingkat kepentingan $24,48 \%$. Hasil evaluasi dari sembilan unsur BMC dengan analsisi SWOT menunjukan kekuatan tertinggi pada unsur Key Partners, kelemahan tertinggi pada unsur Key resources, peluang tertinggi pada Value proposition, dan ancaman tertinggi pada Customer segment.

Pengembangan model bisnis e-commerce MyPertamina dikembangkan melalui unsur Customer Segment dengan menghilangkan segmen awal dengan cara mengganti kendaraan dinas pemerintah, kendaraan dinas swasta, dan mitra transportasi online. Hal lainnya unsur Value proposition seperti prestise, dengan memberikan nilai tambah lebih kepada pengguna MyPertamina dibandingkan dengan customer biasa. Pada unsur Key partners ditambahkan perusahaan swasta sebagai mitra dan sebagai pengguna full service.

Rekomendasi strategi setelah dilakukan pengembangan model bisnis e-commerce MyPertamina ini dimulai dari pemenuhan ekosistem MyPertamina pada semua SPBU COCO (milik Perusahaan) di seluruh Indonesia. Dalam hal ini dilakukan strategi peningkatan layanan produk dengan menyertakan paket full service untuk perusahaan yang ingin menggunakan MyPerta- 
mina dalam menunjang kegiatan operasional bisnisnya.

Menawarkan hubungan kerjasama bisnis dnegan vendor sejenis, yaitu Go-Pay atau OVO, melakukan pembelian bahan bakar di SPBU COCO, adalah memberikan kemudahan dan perasaan prestise kepada pengguna MyPertamina dengan cara memberikan jalur khusus pada pembelian bahan bakar yang menggunakan MyPertamina di SPBU COCO.

\section{UCAPAN TERIMA KASIH}

Ucapan terima kasih disampaikan kepada Bapak Andria Nusa selaku Manager Sales $\mathcal{E}$ Marketing PT. Pertamina Retail yang telah memberikan izin dan fasilitasnya dalam melakukan penelitian di PT Pertamina Retail.

\section{DAFTAR PUSTAKA}

[APJII] Asosiasi Penyelenggara Jasa Internet Indonsia. 2017. Profil Pengguna Internet Indonesia. Jakarta: Asosiasi Penyelenggara Jasa Internet Indonesia (ID). https://apjii. or.id/content/read/39/27/PROFILPENGGUNA-INTERNET-INDONESIA2014 (20 Desember 2018).
[Pertamina Retail]. 2018. Corporate Profile PT. Pertamina Retail 2018. Jakarta (ID).

Drucker, Peter. F, 1996. Inovasi dan Kewiraswastaan yang diterjemahkan oleh Rusjdi Naib. Jakarta (ID): Erlangga.

Giesen, E., S. Berman, R. Bell, A. Blitz. 2007. Path to Succecc Three Ways to innovate Your Business Model. IBM Global Business Service. VOL. 35 No. 6 2007, pp. 27-33.

Kaplan, R.S., D.P. Norton. 2001. Transforming the Balanced Scorecard from Performance Measurement to Strategic Management: Part I. Accounting Horizons: March 2001, 15(1): 87-104. Doi: 10.2308/acch.2001.15.1.87.

Kotler, P. \& Keller. (2008). Manajemen Pemasaran. Edisi Ketigabelas. Jilid 1. Jakarta (ID): Erlangga.

Seider, W.D., Seader \& D.R. Lewin. 2000. Product and Process Design Principles: Synthesis, Analysis, and Evaluation. 2nd Edition.

Stefan, S., B. Richard. 2014. Analysis of business model. Journal of Competitiveness. 6(4): 1940.

Suki, N.M.B., I. Ahmad, dan V. Thyagarajan. 2002. Motivation and concern factors for internet shopping: A Malaysian perspective. The Electronic Journal for E-commerce Tools and Applications 1, 1-18. 